(C) 2015

\author{
Костенко О. М., доктор технічних наук
}

Полтавська державна аграрна академія

\title{
ОПТИМІЗАЦІЯ ПЛАНІВ ЕКСПЕРИМЕНТІВ В УМОВАХ ОБМЕЖЕНИХ МАТЕРІАЛЬНИХ ТА ЧАСОВИХ РЕСУРСІВ
}

\section{Рецензент - доктор технічних наук М. Д. Кочовий}

Стаття присвячена вирішенню науково-технічної проблеми зменшення матеріальних $i$ часових витрат під час реалізаиії експериментальних досліджень за рахунок розробки та впровадження методів синтезу оптимальних планів експериментів в умовах обмежених матеріальних $i$ часових ресурсів. Розроблена методологія включає в собі методи оптимізації за вартісними і часовими витратами планів експерименту: оснований на використанні типових серійних послідовностей планів багатофакторного експерименmу, композиційний метод побудови планів, близьких до оптимальних, побудови каталогу типових планів, ітераційного планування експериментів, послідовного планування експериментів, ідентифікачії динамічних об 'єктів на основі ітераційного планування. Методологія пройшла апробацію під час дослідження низки технологічних проиесів, приладів і систем.

Ключові слова: математичні моделі, обчислювальні методи, оптимізачія, програмноапаратні системи моделювання, методологія, вартісні та часові витрати, планування експериментів.

Постановка проблеми. Експериментальні методи дослідження широко застосовуються у галузях машинобудування, приладобудування, хімічній промисловості під час пошуку розрахунку оптимальної технології, оптимальної конструкції приладів, найвигідніших характеристик систем, співвідношень рецептур, найкращого часу для технологічних процесів. Тому важливого значення набуває систематизація експериментальних досліджень, спрямованих на одержання адекватних математичних моделей процесів. Водночас природним є прагнення експериментаторів оптимізувати параметри виробничих процесів i систем за мінімальними часовими та вартісними витратами. Найбільш перспективними є методи планування активного експерименту, що характеризуються універсальністю і придатністю для використання у багатьох напрямах дослідження.

Проведений аналіз сучасного стану автоматизації експериментальних досліджень технологічних процесів, приладів і систем дав змогу сформулювати основну наукову проблему - зменшення матеріальних i часових витрат під час проведення експериментальних досліджень технологічних процесів, приладів і систем, направлених на математичне моделювання режимів функціонування, за рахунок розробки та впровадження методів синтезу оптимальних планів експериментів в умовах обмежених матеріальних i часових ресурсів.

Аналіз останніх досліджень і публікацій, у яких започатковано розв'язання проблеми. Для підвищення ефективності експериментальних досліджень велике значення має розробка стратегії оптимального планування експерименту, значним внеском у розвиток якої стали роботи Адлера Ю. П. [1], Голікової Т. І. [1], Налімова В. В. [3], Фішера Р. [4, 5], Хінкельмана К. [6], Кастіло С. [7], Чена В. [8], Кокса Д. [9], Рао С. [10] та інших. Проте у розроблених стратегіях доцільно розширити область знаходження оптимальних планів експерименту за рахунок умов обмеження матеріальних та часових ресурсів проведення дослідів. Проблему побудови оптимальних за вартісними або часовими витратами планів експерименту можна вирішувати на основі модифікації існуючих та нових обчислювальних методів і алгоритмів, що враховують особливості реальних технічних та технологічних задач та забезпечують створення ефективних програмних засобів комп'ютерної реалізації методів синтезу оптимальних планів експериментів в умовах обмежених матеріальних і часових ресурсів.

Метою роботи $\epsilon$ зменшення матеріальних $\mathrm{i}$ часових витрат під час проведення експериментальних досліджень за рахунок розробки та впровадження методів синтезу оптимальних планів експериментів в умовах обмежених матеріальних і часових ресурсів.

Для досягнення зазначеної мети поставлені наступні задачі:

- провести аналіз існуючих комбінаторних планів експерименту, критеріїв оптимізації та програмно-апаратних засобів реалізації задач автоматизації експериментів;

- розробити теорію, основану на представленні комбінаторних планів багатофакторного експе- 


\section{TЕХНІЧНІ НАУКИ}

рименту (БФЕ) у вигляді серійних послідовностей;

- розробити методи оптимізації за вартісними та часовими витратами планів експерименту;

Методи дослідження. Під час розв'язання поставленої проблеми використані основні положення теорій комбінаторного аналізу, планування експерименту, символьних послідовностей, множин, моделювання, математичної статистики, оптимізації, програмування, а саме для оптимізації планів експерименту за часовими і вартісними витратами застосовуються комбінаторні методи, теорія символьних послідовностей, теорія множин, а також такі методи оптимізації, як повний перебір, випадковий пошук, гілок і меж, послідовного наближення. Для побудови математичних моделей технологічних процесів, приладів і систем використовуються методи планування експерименту й математичної статистики, а оптимізація цих об'єктів виконується градієнтним методом.

Результати дослідження. Сучасні підходи до реалізації методів планування експерименту призначені розширити технологію промислового планування експерименту і складаються з інтегрованих методів і засобів планування, виконання та аналізу експерименту.

Доведено, що перспективним напрямом $є$ уніфікація і типізація планів експерименту, в основі яких лежить класифікація планів експерименту. Відомі методи, що використовують теорію перерахування комбінаторного аналізу, орієнтовані в основному на окремі види об'єктів, окремі рішення задач і $€$ досить трудомісткими, а формули, що одержуються, дуже громіздкі, а також слабоорієнтовані на вирішення задачі планування експерименту [4]. Тому необхідна розробка нових методів перерахування планів експерименту, що мають певні властивості і дають змогу будувати каталоги типових рішень.

Пропонуємо метод оптимізації планів багатофакторного експерименту на основі серійних послідовностей, який враховує порядок чергування рівнів зміни факторів.

Для формального подання планів БФЕ, що враховують порядок чергування рівнів зміни факторів, розроблена теорія, заснована на поданні комбінаторних планів у вигляді серійних послідовностей.

Показано, що в результаті зміни порядку виконання дослідів змінюється вид послідовностей змі-

$$
\gamma_{i}=\sum_{j=1}^{h} \beta_{j i}, \quad \lambda_{i}=\sum_{j=1}^{h} v_{i} \beta_{j}, \quad \beta_{j}=\left\{\begin{array}{l}
1, a_{j}=\omega_{i} \\
0, a_{j} \neq \omega_{i}
\end{array} .\right.
$$

ни рівнів факторів, відповідних серійних послідовностей та сумарна вартість проведення експерименту. У разі зазначеного подання задача пошуку оптимального варіанта плану БФЕ зводиться до аналізу та пошуку відповідних серійних послідовностей.

Для дослідження властивостей серійних послідовностей, проведення операції над ними розроблена процедура їх побудови. Нехай $\epsilon$ алфавіт $\Omega=\left\{\omega_{1}, \ldots, \omega_{r}\right\}$, що складається $3 r$ символів. Символьною $(r, n)$ послідовністю (Р), яка має довжину $n$, називають послідовність (слово) $P=\left\{p_{1}, \ldots, p_{n}\right\}$, у якій $\quad p_{i} \in \Omega, i=1, \ldots, n$; $n \geq r$ і в послідовності $P$ представлені всі символи 3 алфавіту $\Omega$. Підпослідовність $p_{t+1} p_{t+2} \cdots p_{t+v}$ називається серією $(S)$ в $P$, якщо $p_{t+1}=p_{t+2}=\ldots=p_{t+v} ; p_{t} \neq p_{t+1}$ при $t \geq 1 ; p_{t+v} \neq p_{t+v+1}$, при $t+v \leq n$.

Кількість символів у серії називається довжиною cepiï, $\quad i$-a серія представляється у вигляді $S_{i}\left(a_{i}, v_{i}\right)$, де $a_{i}$ - символ, що утворює серію $i$, $v_{i}$ - довжина серії $i$. Символьна $(r, n)$ послідовність $P$, що складається $3 h$ серій, називається $(r, n, h)$ серійною послідовністю та представляється у вигляді:

$$
P=\left\{S_{1}\left(a_{1}, v_{1}\right), S_{2}\left(a_{2}, v_{2}\right), \ldots, S_{h}\left(a_{h}, v_{h}\right)\right\}
$$$$
\text { де } a_{i} \in \Omega, n=\sum_{i=1}^{h} v_{i} \text {. }
$$

Множина $A=\left\{a_{1}, a_{2}, \ldots, a_{h}\right\} \in$ структурою серійної послідовності, а множина $V=\left\{v_{1}, v_{2}, \ldots, v_{h}\right\}$ - складом серійної послідовності.

Серія $S_{j}\left(a_{j}, v_{j}\right) \in$ серією $i$-го виду, якщо $a_{j}=\omega_{i}$. Кількість серій $i$-го виду $\gamma_{i}$ і кількість символів $i$-го виду $\lambda_{i}$ у послідовності $P$ визначаються в такий спосіб: 
1. Кількість $(r, n)$ послідовностей для $r=2, \ldots, 6, n=2, \ldots, 10$

\begin{tabular}{|c|c|c|c|c|c|c|c|c|c|}
\hline $\mathrm{r} / \mathrm{n}$ & 2 & 3 & 4 & 5 & 6 & 7 & 8 & 9 & 10 \\
\hline 2 & 2 & 6 & 14 & 30 & 62 & 126 & 254 & 510 & 1022 \\
\hline 3 & & 6 & 36 & 150 & 540 & 1806 & 5796 & 18150 & 55980 \\
\hline 4 & & & 24 & 240 & 1560 & 8400 & 40824 & 186480 & 818520 \\
\hline 5 & & & & 120 & 1800 & 16800 & 126000 & 834120 & 5103000 \\
\hline 6 & & & & & 720 & 15120 & 191520 & 1905120 & 16435440 \\
\hline
\end{tabular}

Множини $\Gamma=\left\{\gamma_{1}, \gamma_{2}, \ldots, \gamma_{r}\right\}$ і $\Lambda=\left\{\lambda_{1}, \lambda_{2}, \ldots, \lambda_{r}\right\}$ мають наступні властивості:

$$
\sum_{i=1}^{r} \gamma_{i}=h, \quad \sum_{i=1}^{r} \lambda_{i}=n
$$

На множині символьних послідовностей введені наступні операції.

1. Злиттям послідовності $P^{1}=\left\{S_{1}^{1}\left(a_{1}^{1}, v_{1}^{1}\right), \ldots, S_{h 1}^{1}\left(a_{h 1}^{1}, v_{h 1}^{1}\right)\right\}$ з алфавітом $\Omega_{1}$ і послідовності $P^{2}$ $=\left\{S_{1}^{2}\left(a_{1}^{2}, v_{1}^{2}\right), \ldots, \quad S_{h 2}^{2}\left(a_{h 2}^{2}, v_{h 2}^{2}\right)\right\} \quad 3$ алфавітом $\Omega_{2} \in$ послідовність $P^{3}=\left\{S_{1}^{3}\left(a_{1}^{3}, v_{1}^{3}\right), \ldots\right.$, $\left.S_{h 3}^{3}\left(a_{h 3}^{3}, v_{h 3}^{3}\right)\right\}$ з алфавітом $\Omega_{3}=\Omega_{1} \cup \Omega_{2}$, що позначається $P^{3}=\vartheta\left(P^{1}, P^{2}\right)$. Кількість серій у послідовності $P^{3}$ залежить від виду символів $a_{h 1}^{1}$ i $a_{1}^{2}$.

При $a_{h 1}^{1} \neq a_{1}^{2}$ послідовність $P^{3}$ має вигляд:

$P^{3}=\left\{S_{1}^{1}\left(a_{1}^{1}, v_{1}^{1}\right), \ldots, S_{h}^{1}\left(a_{h}^{1}, v_{h}^{1}\right), S_{1}^{2}\left(a_{1}^{2}, v_{1}^{2}\right), \ldots, S_{h 2}^{2}\left(a_{h 2}^{2}, v_{h 2}^{2}\right)\right\}$,

де $h_{3}=h_{1}+h_{2}$.

При $a_{h 1}^{1}=a_{1}^{2}$ послідовність $P^{3}$ має вигляд:

$$
P^{3}=\left\{S_{1}^{1}\left(a_{1}^{1}, v_{1}^{1}\right), \ldots, S_{h-1}^{1}\left(a_{h-1}^{1}, v_{h-1}^{1}\right), S^{*}\left(a^{*}, v^{*}\right), S_{2}^{2}\left(a_{2}^{2}, v_{2}^{2}\right), \ldots, S_{h 2}^{2}\left(a_{h 2}^{2}, v_{h 2}^{2}\right)\right\},
$$

де $a^{*}=a_{h}^{1}, v^{*}=v_{h 1}^{1}+v_{1}^{2}, h_{3}=h_{1}+h_{2}-1$.

2. Виділення підпослідовності в серійній послідовності $P^{1}=\left\{S_{1}\left(a_{1}, v_{1}\right), S_{2}\left(a_{2}, v_{2}\right), \ldots, S_{h 1}\left(a_{h 1}, v_{h 1}\right)\right\}$ полягає у формуванні послідовності $P^{2}$ виду $S_{\alpha}\left(a_{\alpha}, v_{\alpha}\right), \ldots, S_{\beta}\left(a_{\beta}, v_{\beta}\right)$, тобто виділення серій 3 номерами з $\alpha$ по $\beta$ та позначається $P^{2}=\Theta\left(P^{1}, \alpha, \beta\right)$.

3. Вставка послідовності $P^{2}$ у послідовність $P^{1}$, починаючи $з \mu$-ої серії, визначається як $P^{3}=\Psi\left(P^{1}, P^{2}, \mu\right)=\vartheta\left(\Theta\left(P^{1}, 1, \mu-1\right), P^{2}, \Theta\left(P^{1}, \mu, v_{h 1}^{1}\right.\right.$ та позначається $P^{3}=\Psi\left(P^{1}, P^{2}, \mu\right)$.

4. 3’ єднанням $n$-них послідовностей $P^{1}, P^{2}, \ldots, P^{k}$ називається послідовність $P^{\nabla}$, елементи якої (слова) формуються в спосіб $p^{\nabla}=p_{i}^{1} p_{i}^{2} \ldots p_{i}^{k}$, де $i=1, \ldots, n$ та позначається $P^{\nabla}=\Phi\left(P^{1}, P^{2}, \ldots, P^{k}\right)$. Кількість різних слів у послідовності $P^{\nabla}$ позначене $p$.

Кількість $(r, n)$ послідовностей $L(r, n)$, визначається таким чином:

$$
L(r, n)=r^{n}-\sum_{i=1}^{r-1}\left(L(i, n) \times C_{r}^{i}\right), L(1, n)=1 .
$$

У таблиці 1 наведені значення $L(r, n)$ для $r=2, \ldots, 6, n=2, \ldots, 10$, а в таблиці 2 - кількість $(r, n)$ послідовностей по відношенню до всіх $n$-их послідовностей. 
TEХНIЧНІ НАУКИ

\section{2. Кількість $(r, n)$ послідовностей по відношенню до всіх п-их послідовностей для}

$r=2, \ldots, 6, n=2, \ldots, 10$

\begin{tabular}{|c|c|c|c|c|c|c|c|c|c|}
\hline $\mathrm{r} / \mathrm{n}$ & 2 & 3 & 4 & 5 & 6 & 7 & 8 & 9 & 10 \\
\hline 2 & 50 & 75 & 87,5 & 93,8 & 96,9 & 98,4 & 99,2 & 99,6 & 99,8 \\
\hline 3 & & 22,2 & 44,4 & 61,7 & 74,1 & 82,6 & 88,3 & 92,2 & 94,8 \\
\hline 4 & & & 9,38 & 23,4 & 38,1 & 51,3 & 62,3 & 71,1 & 78,1 \\
\hline 5 & & & & 3,84 & 11,5 & 21,5 & 32,3 & 42,7 & 52,3 \\
\hline 6 & & & & & 1,54 & 5,40 & 11,4 & 18, & 27,2 \\
\hline
\end{tabular}

\section{3. $(3,4)$ послідовності}

\begin{tabular}{|c|c|c|c|c|c|c|c|c|c|c|c|c|c|c|c|c|c|c|c|}
\hline № & $p_{1}$ & $p_{2}$ & $p_{3}$ & $p_{4}$ & № & $p_{1}$ & $p_{2}$ & $p_{3}$ & $p_{4}$ & № & $p_{1}$ & $p_{2}$ & $p_{3}$ & $p_{4}$ & № & $p_{1}$ & $p_{2}$ & $p_{3}$ & $p_{4}$ \\
\hline 1 & 0 & 0 & 1 & 2 & 10 & 0 & 2 & 1 & 1 & 19 & 1 & 1 & 2 & 0 & 28 & 2 & 0 & 1 & 2 \\
\hline 2 & 0 & 0 & 2 & 1 & 11 & 0 & 2 & 1 & 2 & 20 & 1 & 2 & 0 & 0 & 29 & 2 & 0 & 2 & 1 \\
\hline 3 & 0 & 1 & 0 & 2 & 12 & 0 & 2 & 2 & 1 & 21 & 1 & 2 & 0 & 1 & 30 & 2 & 1 & 0 & 0 \\
\hline 4 & 0 & 1 & 1 & 2 & 13 & 1 & 0 & 0 & 2 & 22 & 1 & 2 & 0 & 2 & 31 & 2 & 1 & 0 & 1 \\
\hline 5 & 0 & 1 & 2 & 0 & 14 & 1 & 0 & 1 & 2 & 23 & 1 & 2 & 1 & 0 & 32 & 2 & 1 & 0 & 2 \\
\hline 6 & 0 & 1 & 2 & 1 & 15 & 1 & 0 & 2 & 0 & 24 & 1 & 2 & 2 & 0 & 33 & 2 & 1 & 1 & 0 \\
\hline 7 & 0 & 1 & 2 & 2 & 16 & 1 & 0 & 2 & 1 & 25 & 2 & 0 & 0 & 1 & 34 & 2 & 1 & 2 & 0 \\
\hline 8 & 0 & 2 & 0 & 1 & 17 & 1 & 0 & 2 & 2 & 26 & 2 & 0 & 1 & 0 & 35 & 2 & 2 & 0 & 1 \\
\hline 9 & 0 & 2 & 1 & 0 & 18 & 1 & 1 & 0 & 2 & 27 & 2 & 0 & 1 & 1 & 36 & 2 & 2 & 1 & 0 \\
\hline
\end{tabular}

4. Характеристики $(3,4)$ послідовностей

\begin{tabular}{|c|c|c|c|c|c|c|c|c|c|c|c|c|c|c|c|c|c|c|c|}
\hline \multirow{2}{*}{$\begin{array}{c}\text { № } \\
\text { П/П }\end{array}$} & \multicolumn{4}{|c|}{$A$} & \multicolumn{4}{|c|}{$V$} & \multirow{2}{*}{$T$} & \multirow{2}{*}{$\begin{array}{c}\text { № } \\
\text { П/П }\end{array}$} & \multicolumn{4}{|c|}{$A$} & \multicolumn{4}{|c|}{$V$} & \multirow{2}{*}{$T$} \\
\hline & $a_{1}$ & $a_{2}$ & $a_{3}$ & $a_{4}$ & $v_{1}$ & $v_{2}$ & $v_{3}$ & $v_{4}$ & & & $a_{1}$ & $a_{2}$ & $a_{3}$ & $a_{4}$ & $v_{1}$ & $v_{2}$ & $v_{3}$ & $v_{4}$ & \\
\hline 1 & 0 & 1 & 2 & & 2 & 1 & 1 & & 1 & 19 & 1 & 2 & 0 & & 2 & 1 & 1 & & 13 \\
\hline 2 & 0 & 2 & 1 & & 2 & 1 & 1 & & 2 & 20 & 1 & 2 & 0 & & 1 & 1 & 2 & & 13 \\
\hline 3 & 0 & 1 & 0 & 2 & 1 & 1 & 1 & 1 & 3 & 21 & 1 & 2 & 0 & 1 & 1 & 1 & 1 & 1 & 14 \\
\hline 4 & 0 & 1 & 2 & & 1 & 2 & 1 & & 1 & 22 & 1 & 2 & 0 & 2 & 1 & 1 & 1 & 1 & 15 \\
\hline 5 & 0 & 1 & 2 & 0 & 1 & 1 & 1 & 1 & 4 & 23 & 1 & 2 & 1 & 0 & 1 & 1 & 1 & 1 & 16 \\
\hline 6 & 0 & 1 & 2 & 1 & 1 & 1 & 1 & 1 & 5 & 24 & 1 & 2 & 0 & & 1 & 2 & 1 & & 13 \\
\hline 7 & 0 & 1 & 2 & & 1 & 1 & 2 & & 1 & 25 & 2 & 0 & 1 & & 1 & 2 & 1 & & 17 \\
\hline 8 & 0 & 2 & 0 & 1 & 1 & 1 & 1 & 1 & 6 & 26 & 2 & 0 & 1 & 0 & 1 & 1 & 1 & 1 & 18 \\
\hline 9 & 0 & 2 & 1 & 0 & 1 & 1 & 1 & 1 & 7 & 27 & 2 & 0 & 1 & & 1 & 1 & 2 & & \\
\hline 10 & 0 & 2 & 1 & & 1 & 1 & 2 & & 2 & 28 & 2 & 0 & 1 & 2 & 1 & 1 & 1 & 1 & \\
\hline 11 & 0 & 2 & 1 & 2 & 1 & 1 & 1 & 1 & 8 & 29 & 2 & 0 & 2 & 1 & 1 & 1 & 1 & 1 & 20 \\
\hline 12 & 0 & 2 & 1 & & 1 & 2 & 1 & & 2 & 30 & 2 & 1 & 0 & & 1 & 1 & 2 & & 21 \\
\hline 13 & 1 & 0 & 2 & & 1 & 2 & 1 & & 9 & 31 & 2 & 1 & 0 & 1 & 1 & 1 & 1 & 1 & 22 \\
\hline 14 & 1 & 0 & 1 & 2 & 1 & 1 & 1 & 1 & 10 & 32 & 2 & 1 & 0 & 2 & 1 & 1 & 1 & 1 & 23 \\
\hline 15 & 1 & 0 & 2 & 0 & 1 & 1 & 1 & 1 & 11 & 33 & 2 & 1 & 0 & & 1 & 2 & 1 & & 21 \\
\hline 16 & 1 & 0 & 2 & 1 & 1 & 1 & 1 & 1 & 12 & 34 & 2 & 1 & 2 & 0 & 1 & 1 & 1 & 1 & 24 \\
\hline 17 & 1 & 0 & 2 & & 1 & 1 & 2 & & 9 & 35 & 2 & 0 & 1 & & 2 & 1 & 1 & & 17 \\
\hline 18 & 1 & 0 & 2 & & 2 & 1 & 1 & & 9 & 36 & 2 & 1 & 0 & & 2 & 1 & 1 & & 21 \\
\hline
\end{tabular}


TEХНІЧНI НАУКИ

\section{5. Каталог типових $(3,4)$ серійних послідовностей}

\begin{tabular}{|c|c|c|c|c|c|c|c|c|c|c|c|c|c|c|c|c|c|}
\hline$№$ & $a_{1}$ & $a_{2}$ & $a_{3}$ & $a_{4}$ & Кол. & № & $a_{1}$ & $a_{2}$ & $a_{3}$ & $a_{4}$ & Кол. & № & $a_{1}$ & $a_{2}$ & $a_{3}$ & $a_{4}$ & Кол. \\
\hline 1 & 2 & 3 & 4 & 5 & 6 & 7 & 8 & 9 & 10 & 11 & 12 & 13 & 14 & 15 & 16 & 17 & 18 \\
\hline 1 & 0 & 1 & 2 & & 3 & 9 & 0 & 1 & 2 & 1 & 1 & 17 & 1 & 2 & 0 & 2 & 1 \\
\hline 2 & 0 & 2 & 1 & & 3 & 10 & 0 & 2 & 0 & 1 & 1 & 18 & 1 & 2 & 1 & 0 & 1 \\
\hline 3 & 1 & 0 & 2 & & 3 & 11 & 0 & 2 & 1 & 0 & 1 & 19 & 2 & 0 & 1 & 0 & 1 \\
\hline 4 & 2 & 0 & 1 & & 3 & 12 & 0 & 2 & 1 & 2 & 1 & 20 & 2 & 0 & 1 & 2 & 1 \\
\hline 5 & 1 & 2 & 0 & & 3 & 13 & 1 & 0 & 1 & 2 & 1 & 21 & 2 & 0 & 2 & 1 & 1 \\
\hline 6 & 2 & 1 & 0 & & 3 & 14 & 1 & 0 & 2 & 0 & 1 & 22 & 2 & 1 & 0 & 1 & 1 \\
\hline 7 & 0 & 1 & 0 & 2 & 1 & 15 & 1 & 0 & 2 & 1 & 1 & 23 & 2 & 1 & 0 & 2 & 1 \\
\hline 8 & 0 & 1 & 2 & 0 & 1 & 16 & 1 & 2 & 0 & 1 & 1 & 24 & 2 & 1 & 2 & 0 & 1 \\
\hline
\end{tabular}

Оскільки частка $(r, n)$ послідовностей по відношенню до всіх $n$-их послідовностей істотна, то для побудови множини $(r, n)$ послідовностей можна використовувати послідовну генерацію $n$ розрядних послідовностей $P=\left\{p_{1}, \ldots, p_{n}\right\}, i$-ий елемент якої $p_{i} \in \Omega(i=1, \ldots, n)$, визначати кількість різних символів у послідовності $(\delta)$ і відбирати послідовності з $\delta=r$.

У таблиці 3 наведено приклади $(3,4)$ послідовностей.

Для кожної $(r, n)$ послідовності визначається iï структура $(A)$, склад $(V)$, тип серійної послідовності $(T)$.

Дві серійні послідовності відносяться до одного типу, якщо вони мають однакову структуру $(V)$ і відрізняються складом.

У таблиці 4 наведені характеристики $(3,4)$ послідовностей.

Каталог типових $(3,4)$ серійних послідовностей наведено в таблиці 5.

Мінімальна кількість серій $h_{\min }=r$, при $v_{i}=1$, а максимальна кількість серій $h_{\max }=n$ при $v_{i} \geq 1(i=1, \mathrm{~K}, n)$.

Множина типових серійних $(r, n)$ послідовностей $T(r, n)$ потужністю $G(r, n)$ складається 3 множини типових серійних послідовностей $T(r, n, h) \quad$ потужністю $\quad G(r, n, h) \quad$ для $h=r, \ldots, n$. Значення $G(r, n)$ і $T(r, n)$ визначаються в такий спосіб:

$$
G(r, n)=\sum_{h=r}^{n} G(r, n, h), T(r, n)=\bigcup_{h=1}^{n} T(r, n, h)
$$

Побудова множини $T(r, n)$ складається 3 наступних етапів:

Етап 1. Визначимо, що $h=r$.
Етап 2. Формуємо множину $T(r, n, h)$.

Етап 3. Приймемо $h=h+1$.

Етап 4. Якщо $h>n$, то переходимо до етапу 7.

Етап 5. На основі множини $T(r, n, h-1)$ формуємо множину $T(r, n, h)$.

Етап 6. Переходимо до етапу 3.

Етап 7. Кінець.

Вирішення вказаних етапів побудови множини типових серійних послідовностей розглянуто [5].

Кількість $(r, n)$ послідовностей $W, з$ типовою структурою $A=\left\{a_{1}, a_{2}, \ldots, a_{h}\right\}$, множинами $\quad \Gamma=\left\{\gamma_{1}, \gamma_{2}, \ldots, \gamma_{r}\right\} \quad$ i $\Lambda=\left\{\lambda_{1}, \lambda_{2}, \ldots, \lambda_{r}\right\}$ визначається кількістю композицій $\lambda_{i}$ символів на $\gamma_{i}$ серій $(i=1, \ldots, r)$ :

$$
W=\prod_{i=1}^{r} \delta\left(\lambda_{i}, \gamma_{i}\right), \quad \delta(t, d)=\frac{(t-1) !}{(d-1) !(t-d) !} .
$$

Наприклад, для $A=\left\{a_{1}, a_{2}, a_{1}, a_{2}, a_{3}, a_{2}, a_{3}\right\}, \Gamma=$ $\{2,3,2\}$ и $\Lambda=\{5,4,3\}$ існує 24 варіанта $(3,12)$ послідовностей, склад яких наведений у таблиці 6.

Серійні послідовності планів БФЕ мають особливості, обумовлені властивостями цих планів. При $r=2$ алфавіт $\Omega$ складається із двох символів $\Omega=\left\{\omega_{1}, \omega_{2}\right\}$, які чергуються в послідовності. Стосовно до планів БФЕ, у яких фактори приймають два значення, алфавіт має вигляд: $\Omega=\{-1,+1\}$.

При $k$ факторах і кількості рівнів $r=2$ кількість дослідів $n=2^{k}$. Позначимо кількість серій, утворених символами «-1» через $\gamma^{-}$, а 
утворених символами «+1» через $\gamma^{+}$; кількість символів «-1»у послідовності позначимо через $\lambda^{-}$, а символів «+1»-через $\lambda^{+}$. Множини $\Gamma=$ $\left\{\gamma^{-}, \gamma^{+}\right\}$і $\Lambda=\left\{\lambda^{-}, \lambda^{+}\right\}$мають наступні властивості: $\lambda^{-}=\lambda^{+}=2^{k-1}, \gamma^{-}+\gamma^{+}=h$.

Мінімальна кількість серій $h_{\min }=2$, а максимальна кількість серій $h_{\max }=n / 2$. Значення $\gamma^{-}$i $\gamma^{+}$залежать від значення $h$ і виду типової структури послідовності $A$. В таблиці 7 наведені приклади типових структур $(2,8)$ послідовностей.
Аналіз таблиці 7 показав, що значення $\gamma-$ и $\gamma+$ залежать від того, яке значення $\mathrm{h}$ - парне чи непарне.

У таблиці 8 наведені значення $\gamma-$ и $\gamma+$ в залежності від значення $\mathrm{h}$ та виду типової структури послідовності (А).

Кількість $(2, n)$ послідовностей $W_{i}$, з типовою структурою $A_{i}$, множинами $Г \mathrm{i}=\{\gamma \mathrm{i}-, \gamma \mathrm{i}+\}$ i $\Lambda \mathrm{i}$ $=\{\lambda \mathrm{i}-, \lambda \mathrm{i}+\}$ визначається в такий спосіб:

$$
W_{i}=\delta\left(2^{k-1}, \gamma_{i}^{-}\right) \times \delta\left(2^{k-1}, \gamma_{i}^{+}\right. \text {. }
$$

\section{6. Склад послідовностей}

\begin{tabular}{|l|l|l|l|l|l|l|l|l|l|l|l|l|l|l|l|l|l|l|l|l|l|l|l|}
\hline № & v1 & v2 & v3 & v4 & v5 & v6 & v7 & o & v1 & v2 & v3 & v4 & v5 & v6 & v7 & oo & v1 & v2 & v3 & v4 & v5 & v6 & v7 \\
\hline 1 & 4 & 2 & 1 & 1 & 2 & 1 & 1 & 9 & 1 & 1 & 4 & 2 & 2 & 1 & 1 & 17 & 3 & 1 & 2 & 1 & 2 & 2 & 1 \\
\hline 2 & 4 & 2 & 1 & 1 & 1 & 1 & 2 & 10 & 1 & 1 & 4 & 2 & 1 & 1 & 2 & 18 & 3 & 1 & 2 & 1 & 1 & 2 & 2 \\
\hline 3 & 4 & 1 & 1 & 2 & 2 & 1 & 1 & 11 & 1 & 1 & 4 & 1 & 2 & 2 & 1 & 19 & 2 & 2 & 3 & 1 & 2 & 1 & 1 \\
\hline 4 & 4 & 1 & 1 & 2 & 1 & 1 & 2 & 12 & 1 & 1 & 4 & 1 & 1 & 2 & 2 & 20 & 2 & 2 & 3 & 1 & 1 & 1 & 2 \\
\hline 5 & 4 & 1 & 1 & 1 & 2 & 2 & 1 & 13 & 3 & 2 & 2 & 1 & 2 & 1 & 1 & 21 & 2 & 1 & 3 & 2 & 2 & 1 & 1 \\
\hline 6 & 4 & 1 & 1 & 1 & 1 & 2 & 2 & 14 & 3 & 2 & 2 & 1 & 1 & 1 & 2 & 22 & 2 & 1 & 3 & 2 & 1 & 1 & 2 \\
\hline 7 & 1 & 2 & 4 & 1 & 2 & 1 & 1 & 15 & 3 & 1 & 2 & 2 & 2 & 1 & 1 & 23 & 2 & 1 & 3 & 1 & 2 & 2 & 1 \\
\hline 8 & 1 & 2 & 4 & 1 & 1 & 1 & 2 & 16 & 3 & 1 & 2 & 2 & 1 & 1 & 2 & 24 & 2 & 1 & 3 & 1 & 1 & 2 & 2 \\
\hline
\end{tabular}

7. Типові структури $(2,8)$ послідовностей

\begin{tabular}{|c|c|c|c|c|c|c|c|c|c|c|c|c|c|c|c|c|c|}
\hline № & $a_{1}$ & $a_{2}$ & $a_{3}$ & $a_{4}$ & $a_{5}$ & $a_{6}$ & $a_{7}$ & $a_{8}$ & № & $a_{1}$ & $a_{2}$ & $a_{3}$ & $a_{4}$ & $a_{5}$ & $a_{6}$ & $a_{7}$ & $a_{8}$ \\
\hline 1 & -1 & +1 & & & & & & & 8 & +1 & -1 & +1 & -1 & +1 & & & \\
\hline 2 & +1 & -1 & & & & & & & 9 & -1 & +1 & -1 & +1 & -1 & +1 & & \\
\hline 3 & -1 & +1 & -1 & & & & & & 10 & +1 & -1 & +1 & -1 & +1 & -1 & & \\
\hline 4 & +1 & -1 & +1 & & & & & & 11 & -1 & +1 & -1 & +1 & -1 & +1 & -1 & \\
\hline 5 & -1 & +1 & -1 & +1 & & & & & 12 & +1 & -1 & +1 & -1 & +1 & -1 & +1 & \\
\hline 6 & +1 & -1 & +1 & -1 & & & & & 13 & -1 & +1 & -1 & +1 & -1 & +1 & -1 & +1 \\
\hline 7 & -1 & +1 & -1 & +1 & -1 & & & & 14 & +1 & -1 & +1 & -1 & +1 & -1 & +1 & -1 \\
\hline
\end{tabular}

8. Значення $\gamma^{-}$и $\gamma^{+}$в залежності від значення

\begin{tabular}{|c|c|c|c|}
\hline $\mathrm{h}$ & A & $\gamma^{-}$ & $\gamma^{+}$ \\
\hline \multirow{2}{*}{$\begin{aligned} & 2 \times \tau, \\
\tau= & 1, \ldots, 2^{\mathrm{k}-1}\end{aligned}$} & $-1,+1, \ldots,-1,+1$ & $\mathrm{~h} / 2$ & $\mathrm{~h} / 2$ \\
\hline & $+1,-1, \ldots,+1,-1$ & $\mathrm{~h} / 2$ & $\mathrm{~h} / 2$ \\
\hline \multirow{2}{*}{$\begin{array}{c}\mathrm{h}=2 \times \tau+1, \\
\tau=1, \ldots, 2^{\mathrm{k}-1}-1\end{array}$} & $-1,+1, \ldots,+1,-1$ & {$[\mathrm{~h} / 2]+1$} & {$[\mathrm{~h} / 2]$} \\
\hline & $+1,-1, \ldots,-1,+1$ & {$[\mathrm{~h} / 2]$} & {$[\mathrm{h} / 2]+1$} \\
\hline
\end{tabular}


TEХНІЧНІ НАУКИ

\section{9. Послідовності зміни рівнів факторів планів БФЕ для $k=3$}

\begin{tabular}{|c|c|c|}
\hline $\mathrm{h}$ & $\mathrm{A}$ & $\mathrm{V}$ \\
\hline 2 & $-1,+1$ & $(4,4)$ \\
\hline 2 & $+1,-1$ & $(4,4)$ \\
\hline 3 & $+1,-1,+1$ & $(2,4,2),(1,4,3),(3,4,1)$ \\
\hline 3 & $-1,+1,-1$ & $(3,4,1),(2,4,2),(1,4,3)$ \\
\hline 4 & $-1,+1,-1,+1$ & $(1,2,3,2),(2,3,2,1),(3,2,1,2),(1,3,3,1),(1,1,3,3)$, \\
& $(2,1,2,3),(3,1,1,3),(2,2,2,2),(3,3,1,1)$ \\
\hline 4 & $+1,-1,+1,-1$ & $(2,2,2),(3,2,1,2),(3,3,1,1),(2,3,2,1)$, \\
& & $(2,1,2,3),(1,1,3,3),(3,1,1,3),(1,3,3,1)$ \\
\hline 5 & $-1,+1,-1,+1,-1$ & $(1,3,1,1,2),(1,1,1,3,2),(1,2,1,2,2)$, \\
& & $(1,2,2,2,1),(1,1,2,3,1),(2,1,1,3,1)$, \\
& & $(2,2,1,2,1),(1,3,2,1,1),(2,3,1,1,1)$ \\
\hline 5 & $+1,-1,+1,-1,+1$ & $(1,2,1,2,2),(1,1,1,3,2),(1,1,2,3,1)$, \\
& & $(2,1,1,3,1),(2,2,1,2,1),(2,3,1,1,1)$, \\
& & $(1,2,2,2,1),(1,3,1,1,2),(1,3,2,1,1)$ \\
\hline 6 & $-1,+1,-1,+1$, & $(1,2,1,1,2,1),(1,2,2,1,1,1),(1,1,1,1,2,2)$, \\
& $-1,+1$ & $(1,1,2,1,1,2),(2,1,1,1,1,2),(2,2,1,1,1,1)$, \\
& & $(2,1,1,2,1,1),(1,1,2,2,1,1),(1,1,1,2,2,1)$ \\
\hline 6 & $-1,+1,-1,+1$, & $(1,1,1,2,2,1),(1,2,1,1,2,1),(1,2,2,1,1,1)$, \\
& $-1,+1$ & $(2,2,1,1,1,1),(1,1,2,1,1,2),(1,1,1,1,2,2)$, \\
& & $(2,1,1,2,1,1),(1,1,2,2,1,1),(2,1,1,1,1,2)$ \\
\hline 7 & $-1,+1,-1,+1$, & $(1,1,1,2,1,1,1),(1,1,1,1,1,2,1)$, \\
& $-1,+1,-1$ & $(1,2,1,1,1,1,1)$ \\
\hline 7 & $+1,-1,+1,-1$, & $(1,1,1,2,1,1,1),(1,1,1,1,1,2,1)$, \\
& $+1,-1,+1$ & $(1,2,1,1,1,1,1)$ \\
\hline
\end{tabular}

Для типових $(2, n)$ послідовностей $G(2, n)=2^{k+1}-2$, отже, загальна кількість $(2, n) \quad$ послідовностей $\quad W(2, n)$ $W(2, n)=\sum_{i=1}^{2^{k+1}-2} \delta\left(2^{k-1}, \gamma_{i}^{-}\right) \times \delta\left(2^{k-1}, \gamma_{i}^{+}\right)$

Для побудови множини типових структур $(2, n)$ послідовностей необхідно сформувати послідовності наступного виду:

$$
\begin{aligned}
& \text { а) } P=\vartheta\left(\tau P^{-+}\right), \tau=1, \ldots, 2^{k-1} ; \\
& \text { б) } P=\vartheta\left(\tau P^{+-}\right), \tau=1, \ldots, 2^{k-1} ; \\
& \text { в) } P=\vartheta\left(\tau P^{-+}, P^{-}\right), \tau=1, \ldots, 2^{k-1}-1 ; \\
& \text { г) } P=\vartheta\left(\tau P^{+-}, P^{+}\right), \tau=1, \ldots, 2^{k-1}-1, \\
& \text { де } \\
& P^{-+}=(-1,+1) ; P^{+-}=(+1,-1) ; P^{+}=(+1) ; P^{-}=(-1), \\
& \text { запис } \tau P \text { означає, що послідовність утворена } 3 \\
& \tau \text { послідовно з'єднаних послідовностей } P . \\
& \text { у таблиці } 9 \text { наведено приклади послі- } \\
& \text { довностей зміни рівнів факторів планів БФЕ для } \\
& \text { в=3. }
\end{aligned}
$$

Для автоматизації процесу аналізу серійних послідовностей і побудови каталогів типових представників розроблене програмне забезпечення [6].

Висновок. Для формального представлення планів багатофакторного експерименту, що враховують порядок зміни рівнів факторів, розроблено теорію, основану на представленні комбінаторних планів у вигляді серійних послідовностей.

Досліджені властивості серійних послідовностей, проведені операції над ними, розроблена процедура їх побудови. Показано, що в результаті зміни порядку реалізації дослідів змінюється вид послідовності та сумарна вартість проведення експерименту.

Для вказаного представлення задача пошуку оптимального варіанту плану багатофакторного експерименту зводиться до побудови множини типових планів 3 мінімальною кількістю змін рівнів факторів та до визначення множини серійних послідовностей, на основі яких будуються ці плани.

А потім пошук оптимального варіанта плану БФЕ для заданої вартості зміни рівнів проводити серед типових варіантів, кількість яких значно менша, ніж загальна кількість можливих планів багатофакторних експериментів. 


\section{БІБЛІОГРАФІЯ}

1. Адлер Ю. П. Планирование эксперимента при поиске оптимальных условий (программное введение в планирование эксперимента) : [текст] / Ю. П. Адлер, Е. В. Маркова, Ю. В. Грановский. М. : Наука, 1971. -283 с.

2. Голикова Т. И. Каталог планов второго порядка : [текст] / Т. И. Голикова, Л. А. Панченко, М. 3. Фридман. - М. : Изд-во Моск. ун-та. 1974. - Ч. 2, Вып. 47. - 387 с.

3. Налимов В.Н. Логические основания планирования эксперимента : [текст] / В.Н.Налимов. - М. : Колос, 2001. -280 с.

4. Костенко Е. М. Сравнительный анализ методов оптимизации многофакторных планов эксперимента / Е. М. Костенко, Н. Д. Кошевой, О. Л. Бурлеев // Автоматизированные системы управления и приборы автоматики. - Х. : ХНУРЭ, 2010. - Вып. 150. - С. 60-64.

5. Костенко Е. М. Метод построения оптимальных планов многофакторного эксперимента на основе символьных последовательностей // Современные научные исследования и инновации. Март, 2013 [Электронный ресурс]. - Режим доступа : URL: htth://web.snauka.ru/issues/2013/03/ 23024.

6. Програмні засоби для оптимізації планів експерименту за часовими і вартісними витратами / [Кошовий М. Д., Костенко О. М., Дергачов В. А. та ін.] : зб. наук. праць Національного гірничого університету. - Дніпропетровськ : НГУ, 2011. T. 1. - №36. - C. 76-82.

7. Aldrich $J$. Information and economics in Fisher's design of experiments : [text] / J. Aldrich // International statistical review. - 2007. - V. 75. №2. - P. 131-149.

8. Rao C. R. Fisher: The Founder of Modern Statistics : [text] / C. R. Rao // Statistic textbooks and monographs. -2000 . - V. 161. - P. 311-350.

9. Hinkelmann $K$. Design and Analysis of Experiments, Vol. 1: Introduction to Experimental Design : [text] / K. Hinkelmann, O. Kempthorne. New York : John Wiley \& Sons, 2008. - 248 p.

10. Castillo E. Del Process Optimization: A Statistical Approach : [text] / E. Castillo. Springer-Verlag, 2007. $-380 \mathrm{p}$.

11. Chen V.C. A review on design, modeling and applications of computer experiments : [text] / V. C. Chen // IIE transactions. - 2006. - V. 38. - №4. - P. 273291.

12. Cox D.R. The theory of the design of experiments : [text] / D. R. Cox, N. Reid. - CRC Press, 2000. -292 p.

13. Rao C. R. Combinatorics and Applications to Experimental Designs : [text] / C. R. Rao, D. R. Rao // Electronic Notes in Discrete Mathematics. - 2003. V. 15. - P. 154-162. 